\title{
Stem cells labeled with superparamagnetic iron oxide nanoparticles in a preclinical model of cerebral ischemia: a systematic review with meta-analysis
}

\author{
Leopoldo P Nucci ${ }^{1,2+}$, Helio R Silva ${ }^{1,3+}$, Viviana Giampaoli ${ }^{4}$, Javier B Mamani ${ }^{1}$, Mariana P Nucci ${ }^{5}$ \\ and Lionel F Gamarra ${ }^{1,2,3 *}$
}

\begin{abstract}
Introduction: Although there is an increase in clinical trials assessing the efficacy of cell therapy in structural and functional regeneration after stroke, there are not enough data in the literature describing the best cell type to be used, the best route, and also the best nanoparticle to analyze these stem cells in vivo. This review analyzed published data on superparamagnetic iron oxide nanoparticle (SPION)-labeled stem cells used for ischemic stroke therapy.

Method: We performed a systematic review and meta-analysis of data from experiments testing the efficacy of cellular treatment with SPION versus no treatment to improve behavioral or modified neural scale outcomes in animal models of stroke by the Cochrane Collaboration and indexed in EMBASE, PubMed, and Web of Science since 2000. To test the impact of study quality and design characteristics, we used random-effects meta-regression. In addition, trim and fill were used to assess publication bias.

Results: The search retrieved 258 articles. After application of the inclusion criteria, 24 reports published between January 2000 and October 2014 were selected. These 24 articles were analyzed for nanoparticle characteristics, stem cell types, and efficacy in animal models.
\end{abstract}

Conclusion: This study highlights the therapeutic role of stem cells in stroke and emphasizes nanotechnology as an important tool for monitoring stem cell migration to the affected neurological locus.

\section{Introduction}

Stroke has ranked recently as the second most common cause of death in the Global Burden of Diseases, Injuries, and Risk Factors Study (2010) [1] and as the third most common cause of disability-adjusted life-years (DALYs) worldwide (2010) [2]. Despite the heterogeneity of global epidemiological data and the measurement bias in places without trained professionals, evidence from developed countries suggests that one out of 20 adults (more than

\footnotetext{
* Correspondence: Igamarra@einstein.br

${ }^{\dagger}$ Equal contributors

${ }^{1}$ Hospital Israelita Albert Einstein, Av. Albert Einstein, 627/701, Morumbi, CEP: 05651-901 São Paulo, Brazil

${ }^{2}$ Universidade Federal de São Paulo, Rua Sena Madureira, 1500 - Vila

Clementino, 04021-001 São Paulo-SP, Brazil

Full list of author information is available at the end of the article
}

14 years old) is affected by stroke, and this exceeds the current incidence of acute coronary heart disease. Therefore, stroke constitutes the leading cause of mortality among adults [3].

Conventional clinical management includes percutaneous intravascular interventions and thrombolytic therapy or other medications such as aspirin and behavioral rehabilitation strategies. The wide use of thrombolytic therapy is limited by the narrow time window (within 3 to 4.5 hours after the onset of acute stroke) and serious hemorrhagic complication [4]. Thrombolytic therapy (recombinant tissue plasminogen activator, or rt-PA) is still the most efficient procedure used to restrict neurological damage, although its effectiveness is dependent on and limited to a narrow time window ( 3 to 4.5 hours

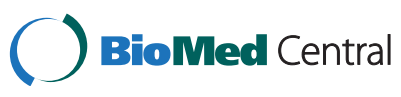

(c) 2015 Nucci et al.; licensee BioMed Central. This is an Open Access article distributed under the terms of the Creative Commons Attribution License (http://creativecommons.org/licenses/by/4.0), which permits unrestricted use, distribution, and reproduction in any medium, provided the original work is properly credited. The Creative Commons Public Domain Dedication waiver (http://creativecommons.org/publicdomain/zero/1.0/) applies to the data made available in this article, unless otherwise stated. 
after the onset of acute stroke) and the risk of severe hemorrhagic complication. Neuroprotective therapies or other procedures, such as erythropoietin (EPO), N-methyl $\mathrm{d}$-aspartate (NMDA) antagonists, and gamma-aminobutyric acid (GABA), have shown positive results in preclinical stroke trials but no evidence of clinical efficacy $[5,6]$.

Given this therapeutic setting, the use of stem cells or stem cell therapy is emerging as a viable option for neurorestorative stroke, especially in cases where the start time of rt-PA exceeded the ideal. The stem cell therapy promotes neuroprotection and neurorepair because of their ability to produce and secrete neurotrophic factors, and it stimulates the replacement of damaged neurons, enabling a favorable neuroimmunomodulation environment for repair $[6,7]$.

The route of administration is crucial for the success of stem cell transplantation because tracking and monitoring of grafted cells are necessary, given the minimum concentration of cells required for the surgery as described earlier. Several techniques using nanoparticlesquantum dots, pebbles, and superparamagnetic iron oxide nanoparticles (SPIONs) [8] - have been described to screen cells in vivo. The iron oxide and magnetic resonance imaging (MRI) can be used not only to evaluate whether the cells have been successfully engrafted but also to monitor the time course of cell migration in the targeted tissue (Figure 1) [9].

This study evaluated functional outcome in publications of the past decade about stem cells labeled with iron oxide nanoparticles in a preclinical ischemic model. Considering reports included in this review, we sought to provide a comprehensive synopsis of preclinical evidence using various donor cell types, their restorative mechanisms, delivery methods, future prospects, and challenges for translating cell therapies as a functional therapy for stroke in clinical settings.

\section{Methods}

\section{Search strategy}

We included reports between January 2000 and October 2014 that were found in the following databases: Cochrane Library, EMBASE, PubMed, and Web of Science. A Boolean strategy was applied. The following sequence of keywords and Boolean operators (DecS/ $\mathrm{MeSH}$ ) were used: EMBASE: 'stem cell'/exp OR 'stem cell' AND ('iron oxide'/exp OR 'iron oxide' OR nanoparticle) AND ('stroke'/exp OR stroke OR 'cerebral ischemia'); PubMed: (((stem cell [MeSH terms]) AND (iron oxide OR SPIO OR nanoparticle)) AND 'cerebral ischemia') OR (((stem cell [MeSH terms]) AND (iron oxide OR SPIO OR nanoparticle)) AND stroke); Web of Science: $\mathrm{TS}=($ stem cell $)$ AND $\mathrm{TS}=$ (nanoparticle) AND $\mathrm{TS}=($ cerebral ischemia $)$ OR TS $=($ stem cell $)$ AND TS $=$ (nanoparticle) AND TS $=($ stroke $)$ OR TS $=($ stem cell $)$ AND TS $=$ (iron oxide) AND $\mathrm{TS}=($ cerebral ischemia $)$ OR TS $=($ stem cell $)$ AND TS $=$ (iron oxide) AND TS = (stroke); Cochrane Library: 'stem cell', 'iron oxide' OR 'nanoparticle' AND 'stroke'.

\section{Data extraction}

Two reviewing authors independently extracted data, screened all references to verify eligibility, and assessed the quality of the trial. Discrepancies in selection of studies and data extraction that appeared between the two reviewers were discussed with a third reviewer and

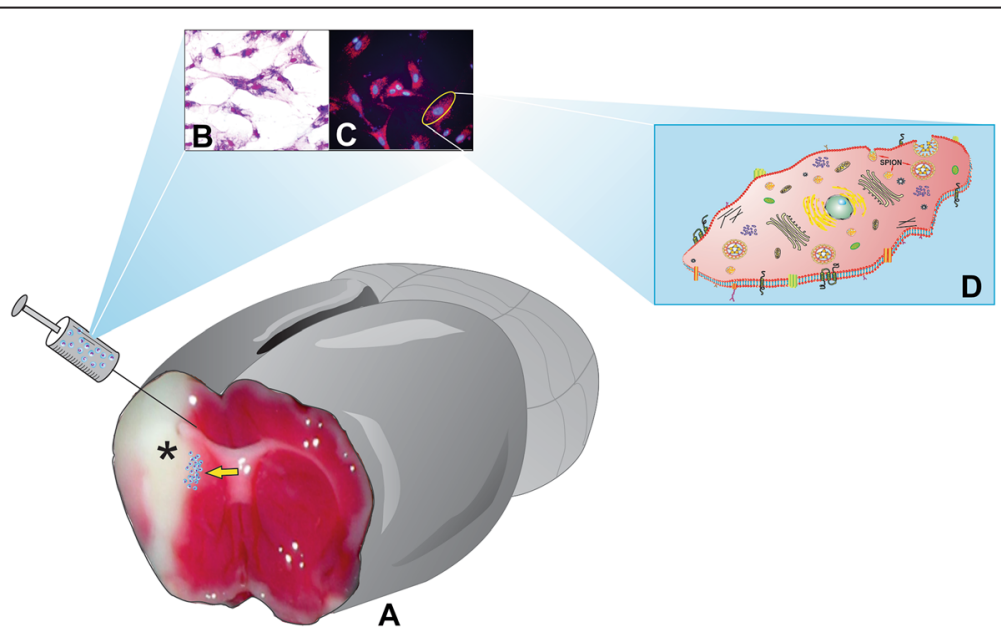

Figure 1 Mesenchymal stem cell therapy after focal ischemia. Rat brain schematic figure of grafting process of the mesenchymal stem cells labeled with superparamagnetic iron oxide nanoparticles after focal ischemia. (A) Coronary rat brain slice staining with 2,3,5-triphenyltetrazolium chloride after occlusion of the middle cerebral artery. (B-C) Umbilical cord of mesenchymal stem cells labeled with superparamagnetic iron oxide nanoparticles, with Prussian blue and rhodamine in fluorescence microscopy, respectively; ${ }^{*}$ focal ischemia. (D) Schematic representation of mesenchymal stem cell interactions with nanoparticles. 
resolved. We undertook a quantitative evaluation of data by using fixed-effect meta-analyses.

\section{Study selection}

Studies included were original reports written in English that used stem cells labeled with paramagnetic iron oxide nanoparticles (SC/SPIONs) in stroke preclinical models published between January 2000 and October 2014. We excluded from this review duplicate reports indexed in more than one database, incomplete articles, studies in conferences, congress or symposium format, book chapters, and publications not in English or those not related to nanoparticles of iron oxide or stem cells (Figure 2).

\section{Statistical analysis}

Data were analyzed by applying a meta-analysis approach [10]. Heterogeneity was evaluated by using the $\mathrm{I}^{2}$ statistic; a considerable heterogeneity $\left(\mathrm{I}^{2}>50 \%\right)$ was explored by using a fixed-effects model by the free software $\mathrm{R}$ version 3.1.0 (Free Software Foundation, Boston, MA, USA).

\section{Results}

In total, 268 articles were identified by the Cochrane Collaboration and indexed in PubMed, Web of Science, and EMBASE. After inclusion criteria were applied, 24 studies were selected (Figure 2). Of these, 20 (83\%) were published within the past 5 years (2008 to 2013). Most (52\%) of the studies were conducted in Asia, followed by the United States and European countries.

The main characteristics of selected studies are presented in Table 1. In regard to the experimental model adopted, one study [11] used dogs, two studies [12,13] used New Zealand rabbits, three studies [14-16] used mice, and other studies (77\%) used rats (200 to $310 \mathrm{~g}$ ). Experimental methods used were the lacunar method in one study [17] and the photothrombosis method in four studies [18-21] conducted in Belgium. These studies used rose Bengal $(10$ or $20 \mathrm{mg} / \mathrm{kg}$ ) for 20 minutes and focused a light beam of $540 \mathrm{~nm}$. In addition, 18 of 19 other studies [11-16,22-33] used the temporary occlusion method of a cerebral vascular bed. Permanent occlusion was reported only in studies by Reddy et al. [12], Gutiérrez-Fernández et al. [34], Wang et al. [35], and Tarulli et al. [32]. The remaining studies performed temporary occlusion, which ranged from 5 minutes $[13,16,31]$ to 120 minutes $[24,25,28]$. The most common vascular beds used were the middle cerebral artery as well as the internal carotid artery of rabbits (New Zealand) [12,34] and the common carotid artery of rats [13].

The labeling cells with SPIONs in most studies $[13,14,18,20,24-27,34]$ were Feridex (or Endorem), four studies [13,19-21] used Resovist, two studies [20,22] used Sinerem, and one study [13] used FluidMag-D, FluidMag-lipid, DEAE-FluidMag, FluidMag-P, and
FluidMag-Q. One study [29] used fluorescent iron nanoparticles (excitation $480 \mathrm{~nm}$ and emission $250 \mathrm{~nm}$ ). In addition to the 13 studies that evaluated commercial nanoparticles, four studies [12,15,19,30] evaluated nanoparticles synthesized in the lab: (i) Lee et al. [19] used nanoparticles synthesized from co-precipitation and polymerization processes; however, these processes were changed to obtain nanoparticles of different diameters, such as 100 to $750 \mathrm{~nm}$; (ii) Reddy et al. [12] used magnetic nanoparticles synthesized by the sonochemical method followed by coating with the Chitosana process; (iii) in the study by Wang et al. [15], synthesis occurred in two stages: the first stage generated synthesis of magnetite nanocluster polystyrene (PMNC), and the second promoted a PMNC coat with silica and rhodamine layer.

For cell process 1, the study [21] used adult progenitor cells, two studies $[26,27]$ used neural lineages, and 13 studies used mesenchymal stem cells (MSCs). Of these 13 trials, four did not specify the cell tissue origin $[13,18,20,24]$, four extracted mesenchymal cells from bone marrow [12,25,29,30], one used fetal MSCs [19], and two used stem cells extracted from tibia and femur $[15,34]$.

The majority of cells were from rats [7,18,21,25,30-34]; however, seven studies used human cells [12,19,24,26-29], five studies used mice cells [14-16,20,23], one study used dog cells [11], and one study used rabbit cells [13]. Only one study did not specify cell type [22]. In relation to cell concentration used for labeling with SPION, only four studies reported this information [13,19,25,27]. The study by Walczak et al. [25], among the identified studies, used the highest cell concentration $\left(1 \times 10^{6}\right)$, two studies $[19,27]$ used the same cell concentration $\left(5 \times 10^{5}\right)$, and the study by Riegler et al. [13] used only $10^{4}$ cells. These cells were grown mainly in Dulbecco's modified Eagle's medium (DMEM) culture [2,14,18,19,22,26,27,34]. Of these seven articles, one [26] used DMEM with F12, another [25] used alpha-minimum essential medium $(\alpha-M E M)$ with F12, and Detante et al. [29] used only $\alpha$-MEM without F12. Only one study [13] used a specific culture for MSCs, and the other four studies $[15,20,21,24]$ did not specify the culture medium used. Of selected studies, only five $[13,26,27,29,34]$ reported behavior score; therefore, three $[13,29,34]$ used MSCs, and two used neural [27] or embryology [26] stem cells (Figure 3 ).

When it comes to the analysis of the process of cell labeling with nanoparticles or SPIONs, most studies [12,14,20-22,24-26] used transfection agents. Of these studies, six [12,14,20,21,25,26] used poly(l-lysine) (PLL), one [22] used Fugene, one [24] used protamine sulfate as transfector agent, and one [13] used serum deprivation as a process of internalization. The most common SPION concentration in this process was approximately $374 \mu \mathrm{g} / \mathrm{mL}$, 


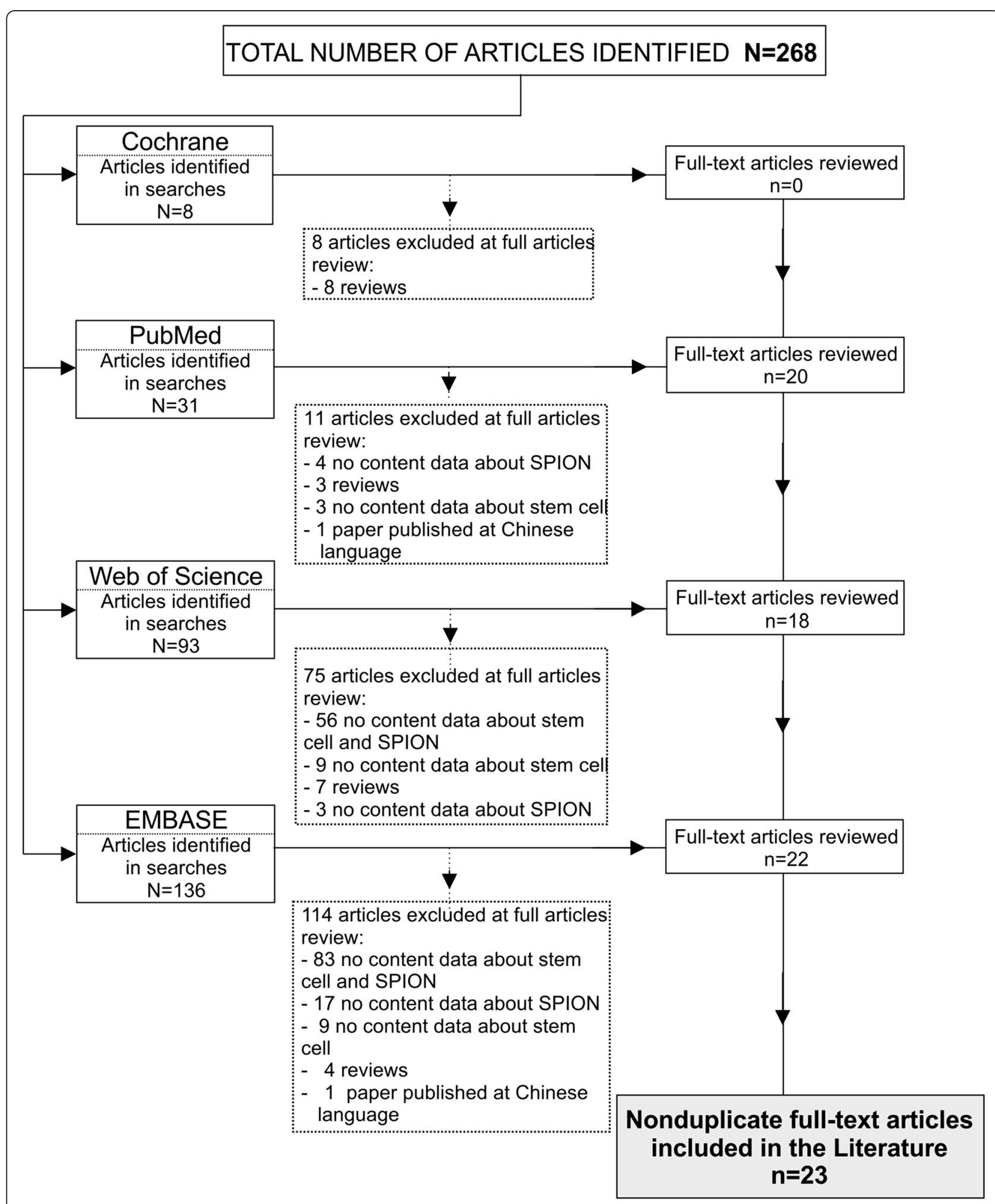

Figure 2 Flowchart of the article screening process for inclusion in this review. SPION, superparamagnetic iron oxide nanoparticle. 
Table 1 Motor performance after therapy with stem cells labeled by iron oxide nanoparticles in experimental designs of stroke

\begin{tabular}{|c|c|c|c|c|c|c|c|c|c|c|c|c|}
\hline \multirow[t]{2}{*}{ Reference } & \multicolumn{3}{|c|}{ Experimental model } & \multicolumn{2}{|l|}{ SPION } & \multirow[b]{2}{*}{ Source } & \multicolumn{4}{|c|}{ Stem cell } & \multicolumn{2}{|c|}{ Behavioral score } \\
\hline & Animal & Type & Type & Type & {$[\mathrm{Fe}] \mu \mathrm{g} / \mathrm{mL}$} & & Type & Concentration & Route & Time & Sham & Lesion \\
\hline Wen et al. [33] (2014) & $\begin{array}{l}\text { Rat } \\
\text { (Sprague-Dawley) }\end{array}$ & MCDA & $T(N / A)$ & In lab & 26 & Rat & NSC & $5 \times 10^{5}$ & Str & $2 d$ & N/A & N/A \\
\hline $\begin{array}{l}\text { Shichinohe et al. } \\
\text { [17] (2013) }\end{array}$ & Rat (Wistar) & Lacunar & $T(N / A)$ & Resovist & 1 & Rat & BMSC & $5 \times 10^{5}$ & Str & $7 d$ & N/A & N/A \\
\hline $\begin{array}{l}\text { Tarulli et al. [32] } \\
\text { (2013) }\end{array}$ & Rat (Long Evans) & MCDA & P & MOC07F, Bang Lab. & 18,8 & $\begin{array}{l}\text { Rat } \\
\text { (femur and tibia) }\end{array}$ & BMSC & $3 \times 10^{6}$ & V & $3 d$ & N/A & N/A \\
\hline $\begin{array}{l}\text { Zhang et al. [16] } \\
\text { (2013) }\end{array}$ & Mice (CD-1) & MCDA & $\mathrm{T}(5 \mathrm{mi})$ & In lab & $5-33$ & Mice & NSC & $5 \times 10^{5}$ & $\mathrm{IC} ; \mathrm{V}$ & $1 \mathrm{~d}$ & N/A & N/A \\
\hline Liu et al. [31] (2013) & $\begin{array}{l}\text { Rat } \\
\text { (Sprague-Dawley) }\end{array}$ & MCDA & $\mathrm{T}(5 \mathrm{mi})$ & In lab & N/A & Rat & NSC & $3 \times 10^{4}$ & Str & $2 d$ & N/A & N/A \\
\hline Lu et al. [11] (2013) & Dog (Beagle) & MCDA & $T(2 h)$ & In lab & N/A & $\begin{array}{l}\text { Dog } \\
\text { (bone marrow) }\end{array}$ & MSC & $3 \times 10^{6}$ & IC & $2 \mathrm{~h}$ & N/A & N/A \\
\hline $\begin{array}{l}\text { Kamiya et al. [30] } \\
(2013)\end{array}$ & $\begin{array}{l}\text { Rat } \\
\text { (Sprague-Dawley) }\end{array}$ & MCDA & $\mathrm{T}(90 \mathrm{mi})$ & In lab & N/A & $\begin{array}{l}\text { Rat } \\
\text { (femur and tibia) }\end{array}$ & MSC & $10^{7}(1 \mathrm{~mL})$ & IC & $\begin{array}{l}90 \\
\mathrm{mi}\end{array}$ & N/A & N/A \\
\hline $\begin{array}{l}\text { Riegler et al. [13] } \\
\text { (2012) }\end{array}$ & $\begin{array}{l}\text { Rabbit } \\
\text { (New Zealand) }\end{array}$ & OAF & $\mathrm{T}(5 \mathrm{mi})$ & $\begin{array}{l}\text { FluidMag-D, FluidMag-lipid, } \\
\text { FluidMag-DEAE, FluidMag, } \\
\text { Endorem, Resovist }\end{array}$ & $16-56.0$ & Rabbit & MSC & $10^{5}(300 \mu \mathrm{L})$ & v & $5 \mathrm{mi}$ & $2.9 \pm 0.93$ & $1.6 \pm 0.38$ \\
\hline $\begin{array}{l}\text { Detante et al. [29] } \\
\text { (2012) }\end{array}$ & $\begin{array}{l}\text { Rat } \\
\text { (Sprague-Dawley) }\end{array}$ & MCDA & T (90 mi) & In lab & 10.0 & $\begin{array}{l}\text { Human } \\
\text { (bone marrow) }\end{array}$ & MSC & $10^{5}(5 \mu \mathrm{L})$ & Str IC & $7 d$ & $3.3 \pm 1.5$ & $1.4 \pm 0.8$ \\
\hline $\begin{array}{l}\text { Yang et al. [28] } \\
\text { (2011) }\end{array}$ & $\begin{array}{l}\text { Rat } \\
\text { (Sprague-Dawley) }\end{array}$ & MCDA & $T(2 h)$ & In lab & 25 & $\begin{array}{l}\text { Human } \\
\text { (bone marrow) }\end{array}$ & MSC & $6 \times 10^{5}$ & IC & $14 \mathrm{~d}$ & N/A & N/A \\
\hline $\begin{array}{l}\text { Wang et al. [15] } \\
\text { (2011) }\end{array}$ & Mice (CD-1) & MCDA & P; T (30 mi) & In lab & N/A & $\begin{array}{l}\text { Mice } \\
\text { (femur and tibia) }\end{array}$ & MSC & $5 \times 10^{5}(1 \mu \mathrm{L})$ & Str & $0 d$ & N/A & $\mathrm{N} / \mathrm{A}$ \\
\hline $\begin{array}{l}\text { Gutiérrez-Fernández } \\
\text { et al. [34] (2011) }\end{array}$ & $\begin{array}{l}\text { Rat } \\
\text { (Sprague-Dawley) }\end{array}$ & MCDA & P & Endorem & 11.2 & $\begin{array}{l}\text { Rat } \\
\text { (femur and tibia) }\end{array}$ & MSC & $2 \times 10^{6}(650 \mu \mathrm{L})$ & ICV & $0 d$ & $3.4 \pm 0.89$ & $1.7 \pm 0.53$ \\
\hline $\begin{array}{l}\text { Vandeputte et al. } \\
\text { [21] (2011) }\end{array}$ & Rat (Fisher 344) & FOT1 & N/A & Resovist & 27.9 & Rat & rMAPC & $10^{6}(1 \mu \mathrm{L})$ & Str & $1 \mathrm{~d}$ & N/A & N/A \\
\hline \multirow{2}{*}{$\begin{array}{l}\text { Reddy et al. [12] } \\
\text { (2010) }\end{array}$} & \multirow{2}{*}{$\begin{array}{l}\text { Rabbit } \\
\text { (New Zealand) }\end{array}$} & $\mathrm{ICAO}$ & \multirow[t]{2}{*}{ P } & \multirow[t]{2}{*}{ Resovist } & \multirow[t]{2}{*}{11.2} & \multirow{2}{*}{$\begin{array}{l}\text { Human } \\
\text { (bone marrow) }\end{array}$} & \multirow[t]{2}{*}{ MSC } & \multirow[t]{2}{*}{$10^{6}(1 \mu \mathrm{L})$} & \multirow[t]{2}{*}{ IC } & \multirow[t]{2}{*}{$4 d$} & \multirow[t]{2}{*}{ N/A } & \multirow[t]{2}{*}{ N/A } \\
\hline & & PPA & & & & & & & & & & \\
\hline \multirow{2}{*}{$\begin{array}{l}\text { Crabbe et al. [20] } \\
\text { (2010) }\end{array}$} & Mice & FOT1 & N/A & \multirow{2}{*}{$\begin{array}{l}\text { Resovist; } \\
\text { Endorem; } \\
\text { Sinerem }\end{array}$} & \multirow[t]{2}{*}{$11.2-27.9$} & \multirow[t]{2}{*}{ Mice } & \multirow[t]{2}{*}{ MSC } & \multirow[t]{2}{*}{$10^{4}-5 \times 10^{6}$} & \multirow[t]{2}{*}{ Str } & \multirow[t]{2}{*}{$2 d$} & \multirow[t]{2}{*}{ N/A } & \multirow[t]{2}{*}{ N/A } \\
\hline & Rat (Fisher 344) & & & & & & & & & & & \\
\hline $\begin{array}{l}\text { Song et al. [27] } \\
\text { (2009) }\end{array}$ & $\begin{array}{l}\text { Rat } \\
\text { (Sprague-Dawley) }\end{array}$ & MCDA & $T(2 h)$ & Feridex & 11.2 & Human & NSC & $4 \times 10^{5}(1 \mu \mathrm{L})$ & Str & $1 d$ & $3.6 \pm 2.1$ & $2.3 \pm 0.42$ \\
\hline $\begin{array}{l}\text { Daadi et al. [26] } \\
\text { (2009) }\end{array}$ & $\begin{array}{l}\text { Rat } \\
\text { (Sprague-Dawley) }\end{array}$ & MCDA & $\mathrm{T}(30 \mathrm{mi} ; 1$ h) & Feridex & 11.2 & Human & ESC & $5 \times 10^{4}-10^{6}(1 \mu \mathrm{L})$ & Str & $2 d$ & $11.5 \pm 7.2$ & $32.4 \pm 12.3$ \\
\hline \multirow[t]{2}{*}{ Lee et al. [19] (2009) } & \multirow[t]{2}{*}{ Rat (Wistar) } & \multirow[t]{2}{*}{ FOT2 } & N/A & $\mathrm{MPIO}$ & $11.2-27.9$ & Human & MSC & $2 \times 10^{4}$ & IC & $2 d$ & N/A & N/A \\
\hline & & & & Resovist & & & & $2 \times 10^{6}$ & V & & & \\
\hline
\end{tabular}


Table 1 Motor performance after therapy with stem cells labeled by iron oxide nanoparticles in experimental designs of stroke (Continued)

\begin{tabular}{|c|c|c|c|c|c|c|c|c|c|c|c|c|}
\hline $\begin{array}{l}\text { Walczak et al. [25] } \\
\text { (2008) }\end{array}$ & Rat (Wistar) & MCDA & $T(2 h)$ & Feridex & 11.2 & $\begin{array}{l}\text { Rat } \\
\text { (bone marrow) }\end{array}$ & MSC & $10^{6}(2 \mu \mathrm{L})$ & V & $\begin{array}{l}30 \\
\mathrm{mi}\end{array}$ & $\mathrm{N} / \mathrm{A}$ & N/A \\
\hline Kim et al. [24] (2008) & $\begin{array}{l}\text { Rat (Sprague- } \\
\text { Dawley) }\end{array}$ & MCDA & $\mathrm{T}(2 \mathrm{~h})$ & Feridex & 11.2 & Human & MSC & $10^{5}$ & IC & $7 d$ & N/A & N/A \\
\hline $\begin{array}{l}\text { Guzman et al. [23] } \\
\text { (2008) }\end{array}$ & $\begin{array}{l}\text { Rat (Sprague- } \\
\text { Dawley) }\end{array}$ & MCDA & $T(1 \mathrm{~h})$ & Feridex & 11.2 & Mice & NSC & $2 \times 10^{5}(2 \mu \mathrm{L})$ & Str & $-7 d$ & N/A & N/A \\
\hline \multirow[t]{2}{*}{ Rice et al. [14] (2007) } & \multirow[t]{2}{*}{ Mice (C57B/6) } & \multirow[t]{2}{*}{ MCDA } & \multirow[t]{2}{*}{$\mathrm{T}(1 \mathrm{~h})$} & \multirow[t]{2}{*}{ Feridex } & \multirow[t]{2}{*}{11.2} & \multirow[t]{2}{*}{ Mice } & \multirow[t]{2}{*}{ fMSC } & $5 \times 10^{2}$ & $\| \mathrm{Hp}$ & \multirow[t]{2}{*}{$1 d$} & \multirow[t]{2}{*}{$3.7 \pm 0.99$} & \multirow[t]{2}{*}{$2.3 \pm 0.48$} \\
\hline & & & & & & & & $5 \times 10^{3}$ & Str & & & \\
\hline \multirow{2}{*}{$\begin{array}{l}\text { Jendelová et al. [18] } \\
\text { (2004) }\end{array}$} & \multirow[t]{2}{*}{ Rat (Wistar) } & \multirow[t]{2}{*}{ FOT2 } & \multirow[t]{2}{*}{ N/A } & \multirow[t]{2}{*}{ Endorem } & \multirow[t]{2}{*}{11.2} & \multirow[t]{2}{*}{ Rat } & ESC & $2 \times 10^{5}$ & IC & \multirow[t]{2}{*}{$7 d$} & \multirow[t]{2}{*}{ N/A } & \multirow[t]{2}{*}{ N/A } \\
\hline & & & & & & & MSC & $2 \times 10^{6}$ & V & & & \\
\hline \multirow{2}{*}{$\begin{array}{l}\text { Hoehn et al. [22] } \\
\text { (2002) }\end{array}$} & \multirow[t]{2}{*}{ Rat (Wistar) } & \multirow[t]{2}{*}{ MCDA } & \multirow[t]{2}{*}{$\mathrm{T}(1 \mathrm{~h})$} & \multirow[t]{2}{*}{ Sinerem } & \multirow[t]{2}{*}{20.0} & \multirow[t]{2}{*}{ N/A } & \multirow[t]{2}{*}{ ESC } & \multirow[t]{2}{*}{$2 \times 3 \times 10^{4}$} & Str & \multirow[t]{2}{*}{$14 \mathrm{~d}$} & \multirow[t]{2}{*}{ N/A } & \multirow[t]{2}{*}{ N/A } \\
\hline & & & & & & & & & $C C$ & & & \\
\hline
\end{tabular}

BMSC, bone marrow-derived mesenchymal stromal cell; CC, corpus callosum; d, day; ESC, embryonic stem cell; fMSC, fat mesenchymal stem cell; FOT1, photothrombosis model (rose Bengal $20 \mathrm{mg} / \mathrm{kg}$, 20 minutes, $540 \mathrm{~nm}$ light); FOT2, photothrombosis model (rose Bengal $10 \mathrm{mg} / \mathrm{kg}$, 10 minutes, light 327 to $650 \mathrm{~nm}$; h, hour; IC, intracortical; ICAO, occlusion of the internal carotid artery; IHp, intrahippocampal; MCDA, occlusion of the middle cerebral artery; mi, minute; MSC, mesenchymal stem cell; N/A, not identified; NSC, neural stem cell; OAF, femoral artery occlusion; P, permanent; PPA, ; rMAPC, rat multipotent adult progenitor cell; SPION, Superparamagnetic iron oxide nanoparticles; MCDA, occlusion of the middle cerebral artery; OAF, femoral artery occlusion; ICAO, Occlusion of the internal carotid artery; FOT1, photothrombosis model (rose Bengal 20 $\mathrm{mg} / \mathrm{kg}, 20 \mathrm{~min}, 540 \mathrm{~nm}$ light); FOT2, photothrombosis model (rose Bengal $10 \mathrm{mg} / \mathrm{kg}, 10 \mathrm{~min}$, light 327 - 650nm: T, temporary; P, Permanent: mi, minute; $h$, hour: N/A, not identified; MOCO7F, MPIO, NSC, neural stem cell; BMSC, bone marrow-derived mesenchymal stroma cell; MSC, mesenchymal stem cells; rMAPC, rat multipotent adult progenitor cell; ESC, embrionary stem cell; Str, intrastriatum; V, endovascular; IC, intracortical; CC, Corpus callosum; IHp, intrahippocampal; fMSC, fat mesenchymal stem cell; d, days. 


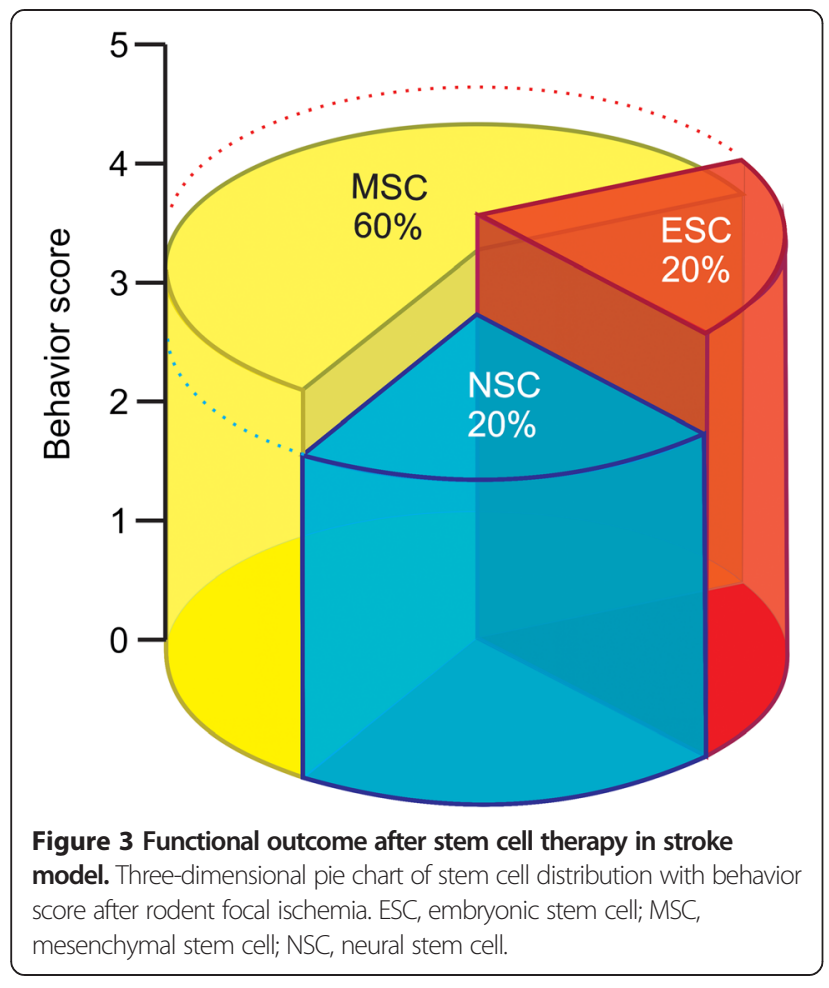

which was identified in five studies [14,18-20,22], but iron concentrations ranged between $0 \mathrm{~g} / \mathrm{mL}$ [13] and $2,800 \mathrm{~g} / \mathrm{mL}$ [22] of $\mathrm{Fe}^{2+}$. In regard to deployment of the $\mathrm{SC} / \mathrm{SPION}$ procedure, the selected studies used cerebral application in specific regions such as striatum $[14,15$, 17,20-23,26,27,29,31,33], hippocampus [14], and corpus callosum [22] and in non-specific regions such as intraventricular/cortical regions [11,12,16,18,19,24,28-30,34]. Some studies [13,16,19,25,32,34] conducted cerebral, internal carotid artery implementation in peripheral, femoral artery, and vascular bed $[13,18,25,34]$. The average time between the ischemic event and therapy with SC/SPION was roughly 3.43 days or 82 hours, but some studies [13,34] underwent implantation immediately after intracortical [34] or endovascular [13]. Another study [22] performed the therapy 14 days after the ischemic event.
The most significant functional recovery was 14 days after implantation of SC/SPION described by GutiérrezFernández et al. [34]. Therapeutic efficacy was evaluated during the experimental model (Figure 4) in only five studies $[13,26,27,29,34]$ that conducted behavioral testing based on adaptations of scales of clinical neurology; other studies have evaluated the efficiency of the model by the analysis of MRI and also by histological analysis (Table 2). No significant influence related to route of administration on either structural or functional outcome was seen.

For the functional outcome, because the Cochran Q test has a low power when the number of studies is small, we consider the $\mathrm{I}^{2}$ statistic to evaluate the heterogeneity of studies. Considering the raw mean difference, we obtained $\mathrm{I}^{2}=19.6 \%$ (confidence interval $(\mathrm{CI})=0 \%$ to $83.3 \%, P=0,2898$ ), indicating that the studies were homogeneous. Therapy was considered effective, as the combined average difference observed was $-1.6255(\mathrm{CI}=$ -1.8923 to $-1.3588, \mathrm{Z}$ statistic $=-11.9446, P<0.0001)$. However, because of experimental methodological differences, we also analyzed the standardized mean differences considering the pooled standard deviation of two groups (Figure 4). In this analysis, the heterogeneity between studies was evident: $\mathrm{I}^{2}=69.1 \%(\mathrm{CI}=20.7 \%$ to $88 \%, P=0.0115)$. However, the conclusions had the same raw mean difference because the combined standardized mean difference observed in fixed effect model was $-1.9161(\mathrm{CI}=-2.2383$ to $-1.5939, \mathrm{Z}$ statistic $=-11.6564, P<0.0001)$. Despite the high heterogeneity among studies on the effectiveness of cell therapy in the cerebrovascular accident model, the analysis indicated a significant neuroprotective effect.

All selected studies [11-34] evaluated the cell homing by using MRI and histological analyses to validate anatomical and functional improvement from results in image evaluation (Table 2). Overall, selected studies regarding MRI found SC/SPIONs homing to ischemic area in several time points and routes. In MRI, the magnetic field ranged from $1.5 \mathrm{~T}[19,27,33]$ to $9.4 \mathrm{~T}[13,14,20,21,25]$. The studies used several protocols of sequence and weighted and thickness images, and the most widely used was a $\mathrm{T}_{2}$-weighted threedimensional spin echo image of $1 \mathrm{~mm}$.

To assess the extent of injury caused by the induced ischemic stroke, nine studies $[11,16,17,19-21,27,30,34]$ were

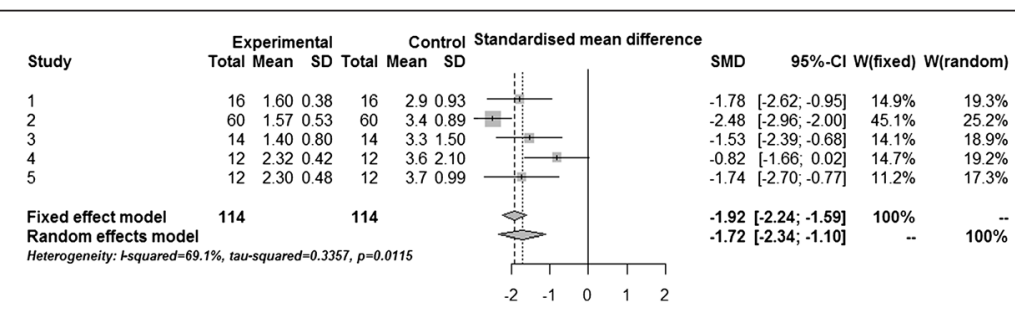

Figure 4 Forest plot of behavior score of stem cell therapy at preclinical stroke. $\mathrm{Cl}$, confidence interval; SD, standard deviation; SMD, standardized mean difference; $W$, weight. 
Table 2 In vivo and Ex vivo image data

\begin{tabular}{|c|c|c|c|c|c|c|c|c|c|}
\hline \multirow[t]{2}{*}{ Reference } & \multirow[b]{2}{*}{ MF $(\mathrm{T})$} & \multicolumn{5}{|c|}{ Magnetic resonance image } & \multicolumn{3}{|l|}{ Histological image } \\
\hline & & Sequence & $\begin{array}{l}\text { Weighted images } \\
\text { (TR/TE;ms) }\end{array}$ & FOV; MT; ST & Results & Date (days) & Assay & Results & Date (days) \\
\hline \multirow[t]{2}{*}{ Wen et al. [33] (2014) } & \multirow[t]{2}{*}{1.5} & FSE & T2:2000/100 & \multirow[t]{2}{*}{$40 ; 256 \times 256 ; 1 \mathrm{~mm}$} & \multirow[t]{2}{*}{$\mathrm{H}+$} & \multirow[t]{2}{*}{$7,14,21,28,35,42$} & \multirow[t]{2}{*}{ PB; GFAP MAP2 } & \multirow[t]{2}{*}{$\mathrm{H}+$} & \multirow[t]{2}{*}{42} \\
\hline & & FFE & $\mathrm{T} 2^{*}: 600 / 18.31$ & & & & & & \\
\hline Shichinohe et al. [17] (2013) & 7.0 & Spin echo & $\mathrm{T} 2: 2500 / 60$ & $30 \times 30 ; 512 \times 512 ; 1 \mathrm{~mm}$ & $\mathrm{H}+$ & $2,8,14,28,49$ & HE; TB; GFAP NeuN & $\mathrm{H}+$ & N/A \\
\hline Tarulli et al. [32] (2013) & 3.0 & FSE & $\mathrm{T} 2: 8 / 70$ & $30 \times 30 ; 512 \times 512 ; 1 \mathrm{~mm}$ & $\mathrm{H}+$ & 7,14 & $\mathrm{~PB}$ & $\mathrm{H}+$ & 15 \\
\hline Zhang et al. [16] (2013) & 7.0 & N/A & N/A & N/A; N/A; & $\mathrm{H}+$ & $1,2,3,4,5,6,7$ & PB & $\mathrm{H}+$ & N/A \\
\hline Liu et al. [31] (2013) & 3.0 & GRE & $T 2^{*}: 2560 / 6.0$ & $6.0 ; \mathrm{N} / \mathrm{A} ; 1.6 \mathrm{~mm}$ & $\mathrm{H}+$ & $1,7,21$ & $\mathrm{~PB} ; \mathrm{BrdU} ; \mathrm{SOX}-2$ & $\mathrm{H}+$ & 7,21 \\
\hline \multirow[t]{2}{*}{ Lu et al. [11] (2013) } & \multirow[t]{2}{*}{3.0} & $\mathrm{~T} 2 \mathrm{Wl}$ & \multirow[t]{2}{*}{$T 2 *: 5000 / 60$} & \multirow[t]{2}{*}{$200 ; 320 \times 320 ; 2 \mathrm{~mm}$} & \multirow[t]{2}{*}{$\mathrm{H}+$} & \multirow[t]{2}{*}{$1,7,14,21,28$} & \multirow[t]{2}{*}{$\mathrm{HE} ; \mathrm{PB}$} & \multirow[t]{2}{*}{$\mathrm{H}+$} & \multirow[t]{2}{*}{28} \\
\hline & & DWI & & & & & & & \\
\hline \multirow[t]{2}{*}{ Kamiya et al. [30] (2013) } & \multirow[t]{2}{*}{7.0} & 3D GRE & $T 2^{*}: 100 / 10$ & $50 \times 50 ; 256 \times 256 ; 5 \mathrm{~mm}$ & \multirow[t]{2}{*}{$\mathrm{H}+$} & \multirow[t]{2}{*}{$1 \mathrm{~h}, 1,3,7$} & \multirow[t]{2}{*}{$\mathrm{BB} ; \mathrm{PKH} 26$} & $\mathrm{H}+$ & \multirow[t]{2}{*}{7} \\
\hline & & $\mathrm{T} 2 \mathrm{Wl}$ & $T 2 *: 2000 / 60$ & $50 \times 50 ; 256 \times 128 ; 5 \mathrm{~mm}$ & & & & $\mathrm{LL}$ & \\
\hline \multirow[t]{2}{*}{ Riegler et al. [13] (2012) } & 9.4 & 3D GRE & $\mathrm{T} 2: 6000 / 105$ & $70 \times 70 ; 512 \times 512 ; 1 \mathrm{~mm}$ & $\mathrm{H}+$ & $24 \mathrm{~h}$ & $\mathrm{~PB}$ & $\mathrm{H}+$ & 21 \\
\hline & & & $\mathrm{T} 2 * 6000 / 105$ & & & & & & \\
\hline Detante et al. [29] (2012) & 2.35 & SE-DW & DW:2000/80 & $\mathrm{N} / \mathrm{A} ; 234 \times 234 ; 1 \mathrm{~mm}$ & $\mathrm{H}+$ & $1,15,28$ & GFAP & $\mathrm{H}+$ & $1,15,28$ \\
\hline & & & $\mathrm{T} 2 * 400 / 25$ & & & & & $\operatorname{Tr}+$ & \\
\hline Yang et al. [28] (2011) & 3.0 & MPGR & $\mathrm{T} 2 *: 596 / 16$ & $292 \times 290 ; 0.7 \mathrm{~mm}$ & $\mathrm{H}+$ & 1,15 & GFAP;PB & $\mathrm{H}+$ & N/A \\
\hline Wang et al. [15] (2011) & 3.0 & N/A & T2: 5840/104 & $45 \times 45 ; 256 \times 256 ; 1.5 \mathrm{~mm}$ & $\mathrm{H}+$ & 1,3 & GFAP;PB & $\mathrm{H}+$ & $1,7,30$ \\
\hline & & & & & $\operatorname{Tr}+$ & & & $\operatorname{Tr}+$ & \\
\hline Gutiérrez-Fernandez et al. [34] & 7.0 & RARE & $\mathrm{T} 2$ & N/A & $\mathrm{H}+$ & $24 h, 14$ & NeuN & $\mathrm{H}+$ & N/A \\
\hline$(2011)$ & & & & & $\mathrm{LL}$ & & GFAP & $\mathrm{LL}$ & \\
\hline & & & & & & & VEGF & & \\
\hline Vandeputte et al. [21] (2010) & 9.4 & N/A & T2: N/A & N/A & $\mathrm{H}+$ & $24 \mathrm{H}, 2-18$ & MAP2 & $\mathrm{H}+$ & N/A \\
\hline & & & & & & & & $\mathrm{Tr}+$ & \\
\hline Reddy et al. [12] (2010) & & Turbo Spin echo & T2: $2128 / 80$ & $230 \times 230 ; 700 \times 625,1 \mathrm{~mm}$ & $\mathrm{H}+$ & 4,16 & $\mathrm{~PB}$ & $\mathrm{H}+$ & 16 \\
\hline & 3.0 & & T2: $2548 / 80$ & $80 \times 80 ; 94 \times 94 ; 1.5 \mathrm{~mm}$ & & & & $\operatorname{Tr}+$ & \\
\hline & & & DW: 4763/50 & $80 \times 80 ; 94 \times 94 ; 1.5 \mathrm{~mm}$ & & & & & \\
\hline Crabbe et al. [20] (2010) & 9.4 & 2D MSME & T2: 6000/10; DW: & $4.0 \times 4.0 ; 156 \times 156 ; 0.8 \mathrm{~mm}$ & $\mathrm{H}+$ & $12 \mathrm{~h}, 10$ & MAP2 & $\mathrm{H}+$ & N/A \\
\hline & & & 1500 & $\mathrm{~N} / \mathrm{A} ; \mathrm{N} / \mathrm{A} ; 1 \mathrm{~mm}$ & & & & $\operatorname{Tr}+$ & \\
\hline Song et al. [27] (2009) & & 3D spin echo & T2: $3500 / 80$ & $60 \times 60 ; 256 \times 1602.0 \mathrm{~mm}$ & N/A & N/A & N/A & N/A & N/A \\
\hline & & & & & & & PB & & \\
\hline & 1.5 & & $\mathrm{~T} 2: 50 / 20$ & $80 \times 80 ; 256 \times 160 ; 2 \mathrm{~mm}$ & $\mathrm{H}+$ & $\begin{array}{l}-1,1,3,7,14,21 \\
28\end{array}$ & NeuN & $\mathrm{H}+$ & 1,28 \\
\hline
\end{tabular}


Table 2 In vivo and Ex vivo image data (Continued)

\begin{tabular}{|c|c|c|c|c|c|c|c|c|c|}
\hline \multirow[t]{3}{*}{ Daadi et al. [26] (2009) } & \multirow[t]{3}{*}{7.0} & \multirow[t]{3}{*}{$2 \mathrm{D}$ - spin echo } & \multirow[t]{3}{*}{ T2: 4000/82,5 } & \multirow[t]{3}{*}{$5 \mathrm{~cm} ; 256 \times 256 ; 0.6 \mathrm{~mm}$} & $\mathrm{H}+$ & \multirow[t]{3}{*}{$2,7,14,28,60$} & hNSC & $\mathrm{H}+$ & \multirow[t]{3}{*}{60} \\
\hline & & & & & \multirow[t]{2}{*}{$\mathrm{LL}$} & & GFP & $\mathrm{LL}$ & \\
\hline & & & & & & & NeuN & & \\
\hline \multirow[t]{2}{*}{ Lee et al. [19] (2009) } & \multirow[t]{2}{*}{1.5} & Turbo spin echo & T2: $2000 / 81$ & \multirow[t]{2}{*}{$5 \mathrm{~cm} ; 512 \times 512 ; 1.5 \mathrm{~mm}$} & \multirow[t]{2}{*}{$\mathrm{H}+$} & \multirow[t]{2}{*}{$-1,1,5,12$} & hVim & $\mathrm{H}+$ & \multirow[t]{2}{*}{ N/A } \\
\hline & & GRE & T2*: 280/20 & & & & fMSC & $\operatorname{Tr}+$ & \\
\hline \multirow[t]{2}{*}{ Walczak et al. [25] (2008) } & \multirow{2}{*}{$\begin{array}{l}4.7 \text { or } \\
9.4\end{array}$} & 3D Spin echo & T2: $1300 / 98$ & $34 \times 22 \times 11 ; 128 \times 64 \times 3 ; 0.35 \mathrm{~mm}$ & \multirow[t]{2}{*}{$\mathrm{H}+$} & \multirow[t]{2}{*}{$-1 h, 2 h-1$} & \multirow[t]{2}{*}{ BrdU } & $\mathrm{H}+$ & \multirow[t]{2}{*}{ N/A } \\
\hline & & GRE & T2*: 300/5 & $10 \times 16 ; 128 \times 128$ & & & & $\operatorname{Tr}+$ & \\
\hline \multirow[t]{3}{*}{ Kim et al. [24] (2008) } & \multirow[t]{3}{*}{4.7} & 3D Spin echo; & $\mathrm{T} 1 ; \mathrm{N} / \mathrm{A}$ & $4 \times 3$ & \multirow[t]{3}{*}{$\mathrm{H}+$} & \multirow[t]{3}{*}{$2,7-70$} & \multirow[t]{3}{*}{ hMSC } & $\mathrm{H}+$ & \multirow{3}{*}{$\begin{array}{l}\text { Cell in core of } \\
\text { lesion }\end{array}$} \\
\hline & & \multirow[t]{2}{*}{ RARE; Flash } & T2: 600/14 & \multirow[t]{2}{*}{$256 \times 192 ; 1 \mathrm{~mm}$} & & & & $\operatorname{Tr}+$ & \\
\hline & & & $\mathrm{T} 2 *: 758 / 30$ & & & & & & \\
\hline \multirow[t]{2}{*}{ Guzman et al. [23] (2008) } & \multirow[t]{2}{*}{4.7} & Spin echo & T2:2500/45 & \multirow[t]{2}{*}{$40 ; 256 \times 256 ; 1 \mathrm{~mm}$} & \multirow[t]{2}{*}{$\mathrm{H}+$} & \multirow[t]{2}{*}{$-4,3,7,24$} & \multirow{2}{*}{$\begin{array}{l}\text { AP BrdU; GFAP; } \\
\text { } \text { Tubulin }\end{array}$} & $\mathrm{H}+$ & \multirow[t]{2}{*}{ N/A } \\
\hline & & 3D GRE & $\mathrm{T} 2 *: 600 / 5$ & & & & & $\operatorname{Tr}+$ & \\
\hline Rice et al. [14] (2007) & 7.0 or & Spin-echo & T2: 1,$0 ; \mathrm{N} / \mathrm{A}$ & $3.5 \mathrm{~cm} ; 128 \times 128 ; 1 \mathrm{~mm}$ & $\mathrm{H}+$ & $24 h, 14$ & fMSC & $\mathrm{H}+$ & N/A \\
\hline & 9.4 & multislice & & & & & GFP & $\operatorname{Tr}+$ & \\
\hline Jendelove et al. [18] (2004) & 4.7 & Turbo spin echo & T2:2000/42.5 & $3,5 \mathrm{~cm} ; 256 \times 256 ; 0,5 \mathrm{~mm}$ & $\mathrm{H}+$ & $14-49$ & $\mathrm{MSC}^{*}$ & $\mathrm{H}+$ & N/A \\
\hline & & & & & & & ESC & $\operatorname{Tr}+$ & \\
\hline & & & & & & & GFP & & \\
\hline Hoehn et al. [22] (2002) & 7.0 & 2D Multislice & T2: 200/20 & $20 \times 12 \times 10256 \times 256 \times 128 ; 0.5-$ & $\mathrm{H}+$ & $6,8,11,16$ & ESC & $\mathrm{H}+$ & N/A \\
\hline & & 3D Flash & & 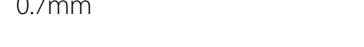 & & & GFP & $\operatorname{Tr}+$ & \\
\hline
\end{tabular}

2D, two-dimensional; 3D, three-dimensional; AP, acidic protein; BrdU, bromodeoxyuridine; DWI, diffusion weighted imaging; ESC, (mouse) embryonic stem cell; FFE, fast field echo; fMSC, fetal mesenchymal stem cell; FOV, field of vision; FSE, fast spin echo; GE, gradient echo ; GFAP, glial fibrillary acidic protein; GFP, green fluorescence protein; GRE, gradient echo; h, hour; HE, hematoxylin and eosin; hMSC, human mesenchymal stem cell; hNSC,human embryonic stem cell-derived human neural stem cell; $\mathrm{H}+$, homing (migration to target site); hVim, human vimentin antibody; LL, loss lesion; MAP2, microtubule-associated with protein 2; $\mathrm{MF}$, magnetic field; MPGR, multiplanar gradient recalled acquisition in the steady state; MSC, rat bone marrow stromal cell; MSME, 2D-Multislice-multiecho; $\mathrm{MT}$, matrix; N/A, not identified; NeuN, neuronal nuclei; PB,
Prussian blue; SE, diffusion-weighted; ST, thickness; RARE, rapid acquisition with relaxation enhancement; $\mathrm{T}$, Tesla; T2WI, -weighted magnetic resonance imaging; T2*, star weighted imaging; TB, Trypan blue; TE, echo time; TR, repetition time; Tr+, tracking (possibility of cellular trace). 
conducted by using the hematoxylin-and-eosin procedure. Results of microscopic analysis of the lesion extent were consistent with findings obtained in the analysis by MRI. Location and extent of injury did not differ considering the experimental model. However, the evaluation of agreement between histology and imaging examination indicated that only three studies $[26,30,34]$ found a decrease in lesion area treated with stem cells. Kamiya et al. [30] and Gutiérrez-Fernández et al. [34] agreed in the short interval between the induction of ischemic stroke and transplantation; that is, they performed the transplantation 90 minutes after induced ischemic stroke; however, Daadi et al. [26] carried out the transplantation 2 days after induced ischemic stroke. In the study by Gutiérrez-Fernández et al. [34], lesion area reduction was independent of the route of administration observed, as Daadi et al. [26] and Kamiya et al. [30] administrated stem cells only in the lesion area.

The homing process of cells used as a therapy was measured in 13 studies [11,12,14,16,18,19,21,24-27,32,33] by Prussian blue staining. Correlation analysis between the location of labeled cells on MRI and location shown on histological analysis indicated agreement between the analyses as well as the homing of positive cells to the area of interest.

In addition the positive cells homing reached the injured organ viability by Prussian blue staining, three studies $[14,18,26]$ assessed expressions by using the green fluorescent protein (GFP) and in all cases the sites indicated by MRI were in agreement. These results confirmed the location of cells and the maintenance of cell viability. Changes in the microenvironment of the lesion reported by four authors $[25,27,31,34]$ that observed increase labeled for bromodeoxyuridine (BrdU) and cell proliferation process. The study by Walczak et al. [25] reported an increase that was positive for BrdU in the perivascular region at the first day after transplantation, and for 10 days after transplantation, positivity was maintained, including more distant regions of the vascular bed. However, despite remaining positive for BrdU, the signal intensity of labeled cells was not maintained in resonance examination. Besides the BrdU labeling, two authors $[27,34]$ conducted labeled for the expression of glial fibrillary acidic protein (GFAP), which is a marker of increased activity of glial cells, especially astrocytes and neuronal nuclei marker (NeuN). In addition, these two studies $[27,34]$ reported increased expression of markers used after transplantation of MSCs, thus indicating increased cell proliferation, glial activity, and preservation of the injured area. In the study by Gutiérrez-Fernández et al. [34], animals treated with MSC markers regardless of the route of administration of labeled cells expressed an increase in addition to BrdU compared with control groups $(137 \pm 9.9$ versus $51 \pm 9.2 ; P<0.05)$. There was also an expression of increase in NeuN, GFAP, and vascular endothelial growth factor (VEGF) after 14 days of transplantation in the penumbra area that contributed toward reducing the injured area and inflammatory markers such as tumor necrosis factor-alpha (TNF- $\alpha$ ) and interleukin-6 (IL-6).

These results appear to correlate with an improvement in neurological scores observed in transplanted animals (3.4 \pm 0.89 versus $1.7 \pm 0.53 ; P<0.05)$. The correlation between increased tissue protective factors in transplanted animals and improved neurological scores was also found in the study by Detante et al. [29] that reported an increase of GFAP in animals that received MSCs and also an improvement in neurological scores in comparison with the control group $(3.3 \pm 1.5$ versus $1.4 \pm 0.8 ; P<0.05)$, thus confirming the results of Gutiérrez-Fernández et al. [34]. Although some studies $[15,17,33]$ did not conduct behavioral assessment, others found an increase in the expression of GFAP and increased microtubule-associated with protein 2 (MAP2), which indicate an improvement in penumbra area.

\section{Discussion}

All selected studies with behavioral tests reported functional improvement associated with the presence of the MS/SPION complex in ischemic area and neurorepair histological changes. The meta-analysis of these studies showed that MS/SPIONs were efficient for treatments, although few studies applied neurological score or behavior tests. Recent reviews [35-37] also observed therapeutic efficacy of stem cells in several preclinical models of stroke but recognized that many fundamental questions related to cell characterization, cell dosage, cell fate, biodistribution, safety indices, outcome measures, and so on are critical for the successful development of a cell product. The labeling process of stem cells with iron oxide could increase cytotoxicity, but improvement of in vivo homing and tracking image techniques of cells.

\section{Could stem cells influence neurorepair after stroke?}

Stem cells come from various sources, and although they share some common properties, they also differ in many respects and behave differently in terms of their rate of differentiation, trophic factor secretion, and their stimulation of endogenous processes when in a pathologic environment [38]. The key source and type of stem cells of the selected studies were human (bone marrow) and mesenchymal. Although the study by Daadi et al. [26] had a better behavior status, using neural embryonic stem cells, the majority of studies used MSCs (60\%), some studies used neural stem cells $(20 \%)$ or embryonic stem cells $(20 \%)$, and no studies compared the different cell types in the same experiment (Figure 3).

The dose or concentration, route, and fate cells of samples of ranged from $5 \times 10^{2}$ (Rice et al. [14] 2007) to $10^{7}$ (Kamiya et al. [30] 2013), and intrastriatal was the main route used. 
A recent meta-analysis [37] on preclinical studies of mesenchymal stromal cells for ischemic stroke observed that the range of MSCs was from $3.5 \times 10^{4}$ to $4.3 \times 10^{7}$, and intravenous was the main route reported in studies. Yavagal et al. [39] evaluated the dose and route of MSCs after 1 hour or 24 hours of ischemic injury per 1 hour of occlusion of the middle cerebral artery, and observed that intra-arterial administration of $1 \times 10^{5}$ MSCs after 24 hours of stroke was more efficient in ameliorating neurological deficits in rodent cerebral ischemia, narrowing change of blood flow, reducing infarct volume, and improving functional status. All selected studies found positive cell tracking of SC/SPIONs by magnetic resonance and histological methods for penumbra area after several routes and times of grafting. Other studies $[40,41]$ and systematic reviews $[35,37]$ also observed several studies with positive stem cell homing to penumbra area after 7 days of stroke. The grafting route can influence the time point and the biodistribution of stem cells and further the aggregation process [37] as previously discussed.

\section{Stem cell biology of repair in preclinical ischemia model}

Among all the lines of stem cells used therapeutically, MSCs can express neuronal markers in vivo as well as trophic factors such as brain-derived neurotrophic factor (BDNF), glial-derived neurotrophic factor (GDNF), VEGF, neurotrophin-3 (NT3), and fibroblast growth factor (FGF), and thrombospondins are secreted by MSCs in response to the local microenvironment. These factors, along with their stimulation of neurogenesis and angiogenesis immunomodulation, promote functional recovery [42]. In this sense, these stem cells also stimulate astrocytes, that this past years has been used as a therapeutic target, because its role in maintaining neuronal function and effective endogenous repair [43]. Most of the selected studies $[11,18,19,21,24-27,32-34]$ observed an increase of trophic factors, reduction of the area of injury, inflammatory markers such as TNF- $\alpha$ and IL-6, increase in protein expression, proliferative activity, and increased activity of glial cells.

\section{Iron toxicity in stem cells}

Although reports evaluated the adoption of methods to assess the ability for differentiation and presence of cytotoxicity, the description of these methods and their results are brief and sometimes treated as irrelevant. This agrees with an understanding that such assessments are not the central idea of the study, because this is a strategy to validate the quality of the cells after labeling with SPIONs, which validate the use for the evaluation of in vivo cell tracking and homing.

The absence of reported cytotoxicity may result from the adoption of methods already established for cultivation and labeling of the cells. A review by Arora et al. [44] reported a study that aimed at standardizing cell labeling with SPIONs, and indicated a low incidence of labeled cells in cytotoxicity because of the concentration of SPIONs, number of cells to be standardized, SPION relationship/cell type, method of internalization, and marking time. This confirms the findings observed in the selected articles. The low incidence of cell death in in vitro cellular genotoxicity and lack of changes in differentiation ability, when contemplating the need for biocompatibility of nanomaterials, contribute to their promising applicability as a contrast agent in stem cell studies [45]. As the selected studies focused on assessing the ability of mapping in vivo homing, cell tracking, and therapeutic potential, the approach of inducing toxicity remained in the background, and was guided by methodological descriptions, which do not allow full clarification of the interaction effects of SPIONs with cellular structures, until the standardization and safety described are achieved. Therefore, because of the brief description of investigation of the cytotoxic effects on marking with SPIONs found in selected studies, our commitment was to further discuss this subject.

Our study has limitations as the internal validity of choice in select only data published in three major database and Cochrane library. In addition, we used an observational approach rather than an experimental one, which enables one to report only associations rather than causation. Although our search strategy was designed to be exhaustive, it is possible that some published studies were missed; nonetheless, our study is likely to have captured the majority of reports in this field and represents the most complete review to date of the use of SC/SPIONs in experimental stroke.

Safety represents a critical concern before stem cells are allowed to be extensively used in clinical settings. Recently, a meta-analysis [38] of clinical trials searched in MEDLINE and EMBASE and by the Cochrane Central Register of Controlled Trials (June 2014) did not detect associations between MSC treatment and development of acute infusional toxicity, organ system complications, infection, death, or malignancy. Notwithstanding these important caveats, our analyses provide a support for some hypotheses regarding the biology of stem cell-based therapies. There is paucity evidence of use of coils with SPION to cell tracking, but this evidence show up the best 'future' outlook in neurological clinical stem cell therapy, because it reduces iron concentration and assists the cell tracking to the brain damage area, and modulates electrophysiology of this area to repair. This review did not identify the use of coils in the selected articles, but explores the evidence regarding the therapeutic use of SPION in preclinical models of stroke.

\section{Conclusions}

Selected studies show great promise for cell transplantation as a new therapeutic modality for stroke. Beneficial effects of 
stem cells might include neuroprotection, angiogenesis, inflammatory, and immune responses. Although animal studies and reviews demonstrated that impaired neural function has been significantly improved after administration of various stem cells, few clinical trials have found similar benefits. A better understanding of the mechanisms of stem cells for treatment of stroke will help resolve the heterogeneity of results. In the future, stem cells combined with gene therapy or rt-PA will play an important role in experimental and clinical settings.

\begin{abstract}
Abbreviations
BrdU: bromodeoxyuridine; Cl: confidence interval; GFAP: glial fibrillary acidic protein; IL-6: interleukin-6; MeSH: Medical Subject Headings; MRI: magnetic resonance imaging; MSC: mesenchymal stem cell; NeuN: neuronal nuclei (marker); rt-PA: recombinant tissue plasminogen activator; SC/SPIONs: stem cells labeled with paramagnetic iron oxide nanoparticles; SPION: superparamagnetic iron oxide nanoparticle; TNF-a: tumor necrosis factor-alpha; VEGF: vascular endothelial growth factor
\end{abstract}

\section{Competing interests}

The authors declare that they have no competing interests.

\section{Authors' contributions}

LPN and HRS contributed to the extracting and screening of all references for eligibility, the assessment of the quality of trials, and drafting the manuscript. LFG contributed to the extracting and screening of all references for eligibility, the assessment of the quality of trials, the conception and coordination of the study, and drafting the manuscript and classified articles as nanoparticles and labeled or synthesis process. When there was divergence between the data extractors, MPN consolidated the data, as described in the methodology by article. VG contributed to the conception of the study and statistical analysis. JBM classified articles as nanoparticles and labeled or synthesis process. All authors read and approved the final manuscript.

\section{Acknowledgments}

This study was funded by the Instituto Israelita de Ensino e Pesquisa Albert Einstein, FINEP/CAPES, FAPESP, and FAPEG. We thank Edna Terezinha Rother and José Belém de Oliveira Neto for the support given during data collection.

\section{Author details}

'Hospital Israelita Albert Einstein, Av. Albert Einstein, 627/701, Morumbi, CEP 05651-901 São Paulo, Brazil. Universidade Federal de São Paulo, Rua Sena Madureira, 1500 - Vila Clementino, 04021-001 São Paulo-SP, Brazil. ${ }^{3}$ Santa Casa Misericórdia de São Paulo, Dr. Cesario Motta Junior, 61 - Vila Buarque, 01221-020 São Paulo-SP, Brazil. " Instituto de Matemática e Estatística, Universidade de São Paulo, Rua do Matão 1010 - Cidade Universitária, 05508-090 São Paulo-SP, Brazil. ${ }^{5}$ LIM44, Universidade de São Paulo, Rua Dr Éneas de Carvalho Aguiar, 255 - Cerqueira César, 05403-000 São Paulo-SP, Brazil.

Received: 18 June 2014 Revised: 26 November 2014 Accepted: 23 February 2015 Published online: 13 March 2015

\section{References}

1. Feigin VL, Forouzanfar MH, Krishnamurthi R, Mensah GA, Connor M, Bennett DA, et al. Global and regional burden of stroke during 1990-2010: findings from the Global Burden of Disease Study 2010. Lancet. 2014;383:245-55.

2. Murray CJ, Vos T, Lozano R, Naghavi M, Flaxman AD, Michaud C, et al. Disability-adjusted life years (DALYs) for 291 diseases and injuries in 21 regions, 1990-2010: a systematic analysis for the Global Burden of Disease Study 2010. Lancet. 2013;380:2197-223.

3. Rothwell PM, Coull AJ, Silver LE, Fairhead JF, Giles MF, Lovelock CE, et al. Oxford vascular study. Lancet. 2005;366:1773-83.

4. Thomalla G, Sobesky J, Köhrmann M, Fiebach JB, Fiehler J, Zaro Weber O, et al. Two tales: hemorrhagic transformation but not parenchymal hemorrhage after thrombolysis is related to severity and duration of ischemia: MRI study of acute stroke patients treated with intravenous tissue plasminogen activator within 6 hours. Stroke. 2007;38:313-8.

5. Auriel E, Bornstein NM. Neuroprotection in acute ischemic stroke-current status. J Cell Mol Med. 2010;14:2200-2

6. Worthmann H, Martens-Lobenhoffer J, Joumaah M, Li N, Lichtinghagen R, Hecker $\mathrm{H}$, et al. Asymmetric dimethylarginine in response to recombinant tissue-type plasminogen activator and erythropoietin in acute stroke. Stroke. 2013;44:2128-33.

7. Zhang ZG, Chopp M. Neurorestorative therapies for stroke: underlying mechanisms and translation to the clinic. Lancet Neurol. 2009;8:491-500.

8. Kubinová S, Syková E. Nanotechnology for treatment of stroke and spinal cord injury. Nanomedicine (Lond). 2010;5:99-108.

9. Borlongan CV, Masuda T, Walker TA, Maki M, Hara K, Yasuhara T, et al. Nanotechnology as an adjunct tool for transplanting engineered cells and tissues. Curr Mol Med. 2007;7:609-18.

10. Villar J, Mackey ME, Carroli G, Donner A. Meta-analyses in systematic reviews of randomized controlled trials in perinatal medicine: comparison of fixed and random effects models. Stat Med. 2001;20:3635-47.

11. Lu SS, Liu S, Zu QQ, Xu XQ, Yu J, Wang JW, et al. In vivo MR imaging of intraarterially delivered magnetically labeled mesenchymal stem cells in a canine stroke model. PLoS One. 2013;8:e54963.

12. Reddy AM, Kwak BK, Shim HJ, Ahn C, Lee HS, Suh YJ, et al. In vivo tracking of mesenchymal stem cells labeled with a novel chitosan-coated superparamagnetic iron oxide nanoparticles using 3.0 T MRI. J Korean Med Sci. 2010;25:211-9.

13. Riegler J, Liew A, Hynes SO, Ortega D, O'Brien T, Day RM, et al. Superparamagnetic iron oxide nanoparticle targeting of MSCs in vascular injury. Biomaterials. 2013;34:1987-94.

14. Rice HE, Hsu EW, Sheng H, Evenson DA, Freemerman AJ, Safford KM, et al. Superparamagnetic iron oxide labeling and transplantation of adiposederived stem cells in middle cerebral artery occlusion-injured mice. AJR Am J Roentgenol. 2007;188:1101-8

15. Wang $Y, X u F$, Zhang $C$, Lei $D$, Tang $Y$, Xu H, et al. High MR sensitive fluorescent magnetite nanocluster for stem cell tracking in ischemic mouse brain. Nanomedicine. 2011;7:1009-19.

16. Zhang L, Wang Y, Tang Y, Jiao Z, Xie C, Zhang H, et al. High MR performance fluorescent mesoporous silica-coated magnetic nanoparticles for tracking neural progenitor cells in an ischemic mouse model. Nanoscale. 2013;5:4506-16.

17. Shichinohe H, Yamauchi T, Saito H, Houkin K, Kuroda S. Bone marrow stromal cell transplantation enhances recovery of motor function after lacunar stroke in rats. Acta Neurobiol Exp (Wars). 2013;73:354-63.

18. Jendelová P, Herynek V, Urdzíková L, Glogarová K, Kroupová J, Andersson B, et al. Magnetic resonance tracking of transplanted bone marrow and embryonic stem cells labeled by iron oxide nanoparticles in rat brain and spinal cord. J Neurosci Res. 2004;76:232-43.

19. Lee ES, Chan J, Shuter B, Tan LG, Chong MS, Ramachandra DL, et al. Microgel iron oxide nanoparticles for tracking human fetal mesenchymal stem cells through magnetic resonance imaging. Stem Cells. 2009;27:1921-31.

20. Crabbe A, Vandeputte C, Dresselaers T, Sacido AA, Verdugo JM, Eyckmans J, et al. Effects of MRI contrast agents on the stem cell phenotype. Cell Transplant. 2010;19:919-36.

21. Vandeputte C, Thomas D, Dresselaers T, Crabbe A, Verfaillie C, Baekelandt V, et al. Characterization of the inflammatory response in a photothrombotic stroke model by MRI: implications for stem cell transplantation. Mol Imaging Biol. 2011;13:663-71.

22. Hoehn M, Küstermann E, Blunk J, Wiedermann D, Trapp T, Wecker S, et al. Monitoring of implanted stem cell migration in vivo: a highly resolved in vivo magnetic resonance imaging investigation of experimental stroke in rat. Proc Natl Acad Sci U S A. 2002;99:16267-72.

23. Guzman R, Bliss T, De Los AA, Moseley M, Palmer T, Steinberg G. Neural progenitor cells transplanted into the uninjured brain undergo targeted migration after stroke onset. J Neurosci Res. 2008:86:873-82.

24. Kim D, Chun BG, Kim YK, Lee YH, Park CS, Jeon I, et al. In vivo tracking of human mesenchymal stem cells in experimental stroke. Cell Transplant. 2008:16:1007-12.

25. Walczak P, Zhang J, Gilad AA, Kedziorek DA, Ruiz-Cabello J, Young RG, et al. Dual-modality monitoring of targeted intraarterial delivery of mesenchymal stem cells after transient ischemia. Stroke. 2008;39:1569-74.

26. Daadi MM, Li Z, Arac A, Grueter BA, Sofilos M, Malenka RC, et al. Molecular and magnetic resonance imaging of human embryonic stem 
cell-derived neural stem cell grafts in ischemic rat brain. Mol Ther. 2009;17:1282-91.

27. Song M, Kim Y, Kim Y, Ryu S, Song I, Kim SU, et al. MRI tracking of intravenously transplanted human neural stem cells in rat focal ischemia model. Neurosci Res. 2009;64:235-9.

28. Yang J, Lee ES, Noh MY, Koh SH, Lim EK, Yoo AR, et al. Ambidextrous magnetic nanovectors for synchronous gene transfection and labeling of human MSCs. Biomaterials. 2011;32:6174-82.

29. Detante O, Valable S, de Fraipont F, Grillon E, Barbier EL, Moisan A, et al. Magnetic resonance imaging and fluorescence labeling of clinical-grade mesenchymal stem cells without impacting their phenotype: study in a rat model of stroke. Stem Cells Transl Med. 2012;1:333-41.

30. Kamiya N, Ueda M, Igarashi H, Nishiyama Y, Suda S, Okubo S, et al. In vivo monitoring of arterially transplanted bone marrow mononuclear cells in a rat transient focal brain ischemia model using magnetic resonance imaging. Neurol Res. 2013;35:573-9.

31. Liu H, Cao J, Zhang H, Qin S, Yu M, Zhang X, et al. Folic acid stimulates proliferation of transplanted neural stem cells after focal cerebral ischemia in rats. J Nutr Biochem. 2013;24:1817-22.

32. Tarulli E, Chaudhuri JD, Gretka V, Hoyles A, Morshead CM, Stanisz GJ. Effectiveness of micron-sized superparamagnetic iron oxide particles as markers for detection of migration of bone marrow-derived mesenchymal stromal cells in a stroke model. J Magn Reson Imaging. 2013;37:1409-18.

33. Wen $X$, Wang $Y$, Zhang F, Zhang $X$, Lu L, Shuai $X$, et al. In vivo monitoring of neural stem cells after transplantation in acute cerebral infarction with dual-modal MR imaging and optical imaging. Biomaterials. 2014;35:4627-35.

34. Gutiérrez-Fernández M, Rodríguez-Frutos B, Alvarez-Grech J, VallejoCremades MT, Expósito-Alcaide M, Merino J, et al. Functional recovery after hematic administration of allogenic mesenchymal stem cells in acute ischemic stroke in rats. Neuroscience. 2011;175:394-405.

35. Lees JS, Sena ES, Egan KJ, Antonic A, Koblar SA, Howells DW, et al. Stem cell-based therapy for experimental stroke: a systematic review and meta-analysis. Int J Stroke. 2012;7:582-8.

36. Hao L, Zou Z, Tian H, Zhang Y, Zhou H, Liu L. Stem cell-based therapies for ischemic stroke. Biomed Res Int. 2014;2014:468748.

37. Vu Q, Xie K, Eckert M, Zhao W, Cramer SC. Meta-analysis of preclinical studies of mesenchymal stromal cells for ischemic stroke. Neurology. 2014;82:1277-86.

38. Kalladka D, Muir KW. Brain repair: cell therapy in stroke. Stem Cells Cloning. 2014;7:31-44.

39. Yavagal DR, Lin B, Raval AP, Garza PS, Dong C, Zhao W, et al. Efficacy and dose-dependent safety of intra-arterial delivery of mesenchymal stem cells in a rodent stroke model. PLoS One. 2014;9:e93735.

40. Guo L, Ge J, Wang S, Zhou Y, Wang X, Wu Y. A novel method for efficient delivery of stem cells to the ischemic brain. Stem Cell Res Ther. 2013;4:116.

41. Karlupia N, Manley NC, Prasad K, Schäfer R, Steinberg GK. Intra-arterial transplantation of human umbilical cord blood mononuclear cells is more efficacious and safer compared with umbilical cord mesenchymal stromal cells in a rodent stroke model. Stem Cell Res Ther. 2014;5:45.

42. Chopp M, Li Y. Treatment of neural injury with marrow stromal cells. Lancet Neurol. 2002;1:92-100.

43. Sofroniew MV. Reactive astrocytes in neural repair and protection. Neuroscientist. 2005;11:400-7.

44. Arora S, Jyutika MR, Kishore MP. Nanotoxicology and in vitro studies: the need of the hour. Toxicol Appl Pharmacol. 2012;258:151-65.

45. Mahmoudi M, Simchi A, Milani AS, Stroeve P. Cell toxicity of superparamagnetic iron oxide nanoparticles. J Colloid Interface Sci. 2009;336:510-8.

\section{Submit your next manuscript to BioMed Central and take full advantage of:}

- Convenient online submission

- Thorough peer review

- No space constraints or color figure charges

- Immediate publication on acceptance

- Inclusion in PubMed, CAS, Scopus and Google Scholar

- Research which is freely available for redistribution

Submit your manuscript at www.biomedcentral.com/submit 